\title{
Managing Difficult Fractures Due To Ballistic Trauma With Ilizarov Ring Fixation
}

\author{
Chand $\mathrm{P}^{1}$, Shrestha $\mathrm{RL}^{2}, \mathrm{KC} \mathrm{BR}^{3}$, Shah $\mathrm{BC}^{4}$, Joshi $\mathrm{A}^{5}$, Thapa $\mathrm{BB}^{6}$ \\ ${ }^{1}$ Pankaj Chand, Consultant Orthopedic Surgeon, Shree Birendra Hospital Chhauni, ${ }^{2}$ Roshan Lal Shrestha, Consultant \\ Orthopedic Surgeon, Model Hospital, Kathmandu, ${ }^{3}$ Bachu Ram KC, Senior Consultant and Orthopedic Surgeon, \\ ${ }^{4}$ Bhanu Chand Shah Consultant and Orthopedic Surgeon, ${ }^{5} \mathrm{Amit}$ Joshi, Orthopedic Surgeon, ${ }^{6}$ Bishnu Bahadur Thapa, \\ Consultant and Orthopedic Surgeon, Shree Birendra Hospital Chhauni
}

\begin{abstract}
20 fractures ( 7 femoral and 13 tibial) were treated with the illizarov apparatus between 2003 to 2006 . All were old injuries, previously managed by internal fixation (intramedullary rods), external fixation (Hoffman's external fixators), or conservatively with traction and plaster of paris slabs. Ilizarov fixators were applied to manage infected non-union with or without bone loss and malunion. Corticotomy and bone transport was carried out in cases with significant bone loss. In others without any limb shortening and minimal bony defect, bone grafting and compression was carried out. In one case valgus deformity along with non-union was corrected. Early weight bearing with range of motion exercises for ankle and knee joints were encouraged. Average fracture healing time was 12 months (8 to18months). All fractures healed with $<5^{\circ}$ of malalignment. Complications included pin site inflammation/ infection, muscle transfixation, knee and ankle joint stiffness and a wire fracture. The ilizarov device provided definitive fixation with acceptable results in all cases.
\end{abstract}

Key words: llizarov ring fixator, distraction osteogenesis, bone transport, infective non-union, corticotomy

\section{Introduction}

Extremity injury as a result of blast trauma commonly results in severe soft-tissue and osseous injury. In one recent military review of soldiers injured in battle, $54 \%$ of all 3575 wounds involved the extremities and $82 \%$ of 915 long-bone fractures were open (1). The tibia and fibula were the most commonly affected lowerextremity long bones.

The treatment of open tibial fractures with aggressive débridement and intramedullary nail insertion followed by soft-tissue coverage has become the standard of care at most civilian trauma centers (2-6). Severe open extremity fractures resulting from blast injuries during wartime and characterized by an "outside-in" mechanism with extensive contamination and delays in treatment due to evacuation are distinct injuries compared with civilian injuries and may be better treated by avoiding placement of internal fixation. (7-12).

Their treatment, prognosis, and outcome are mainly determined by the mechanism of injury, degree of resulting comminution, soft tissue injury and displacement. Fractures produced by indirect trauma have a better prognosis than those produced by direct trauma. The risk of delayed union and nonunion in closed and open treatment is increased with comminution. Open fractures have a higher infection rate than closed fractures and the rate increases with the increasing

Address for Correspondence: pankreena@hotmail.com 
severity of the soft tissue injury. High-energy injuries have added to the number and complexity of fractures of long bones, especially those of tibia and so have the treatment modalities addressing them. War injuries are peculiar as they incorporate severe soft tissue trauma, with bacterial contamination, along with the possibility of a vascular injury. The fracture itself might be severely comminuted, with or without bone loss. Almost always they are high velocity injuries. Thus the orthopaedic surgeon is often faced with non-united or mal-united fractures, bones and soft tissue defects, persistent infections and sometimes the need for amputation.

Ilizarov method addresses most problems, allowing early weight bearing ambulation and joint mobilisation. Progressive bone histogenesis following corticotomy and bone transport helps in filling bone gaps eradicating infection and promoting fracture union. Infection control is achieved by radical debridement of the infected tissues including bone and followed by bone transport to reconstruct the residual bone defect.

We evaluated the use of llizarov device as the mode of fracture stabilization of these difficult fractures and present our experience of Ilizarov fixation in the treatment of established recalcitrant infected nonunions and gap non-unions of the tibia and femur and the suitability of this procedure with particular reference to bony union and to identify the factors influencing the functional outcomes.

\section{Methods}

Twenty patients with established infected non-union of the tibia (sixteen) and femur (four) were included for the study. One patient had an unacceptable varus angulation of $14^{\circ}$ of the tibia. The patients were followed up over a 5 year period from the day of Ilizarov fixator application.

Clinical history including co-morbidities, social habits including smoking and alcohol consumption, previous treatment offered for the fracture, complications, duration of nonunion, were gathered. Seventeen patients were serving soldiers, while the three female patients were all housewives. All the male patients were active and sole earners of their families with no additional source of income.

The initial diagnosis was Gustilo type II open fracture in 1, Type IIIA in 5, IIIB in 12 and type IIIC in 2 patients. 10 patients had extensive bone loss at the time of initial injury. Initially, after debridement, 8 patients had internal fixation device [intra-medullary nail in 6 and plate and screw fixation in 2] applied and, 10 had external fixation with Hoffman's uniplanar fixators while two were managed conservatively with plaster immobilization.

All patients had preoperative full-length radiographs of the affected limb for assessment of the level and type of fracture nonunion, plane of deformity, bone quality and presence of sequestrum. They were counseled about the procedure to be performed, and the expected outcome of treatment. Culture swabs from draining sinuses and open wounds were carried out in all patients and appropriate antibiotic therapy was initiated. This was repeated whenever necessary throughout the duration of treatment.

4 patients with internal fixation had had fasciocutaneous or muscle flap coverage for the open wounds prior to application of ring fixator. One, with a varus deformity underwent correction of the defect while in the llizarov frame. For two patients who had femoral artery rupture, vascular reconstruction was carried out with autologus saphenous vein graft when they were first brought in.

The average duration of non-union and time of Ilizarov fixation was 7.8 months. Limb shortening ranged from 2 - $11 \mathrm{cms}$ and bone gap ranged from 2-9 cms. 15 patients had associated fibular shaft fractures, which had healed at the time Ilizarov application. Pus culture in all patients obtained pre operatively, revealed a mixed a bacterial growth.

The llizarov frame was constructed pre-operatively in all patients. 15 patients with limb shortening and significant bone loss had debridements combined with ring fixator application as a single stage procedure. Corticotomy was carried out in these patients followed by bone transport. All patients had bifocal osteosynthesis [compression of the fracture site with bone transport following corticotomy]. Five of these were given additional bone graft when docking was achieved.. In four patients with no limb shortening and minimal bone loss, after debridement, the fracture site was freshened, and acute docking was carried out after instituting autogenous bone graft along with fibular osteotomy. In one patient the ilizarov frame was applied to rectify valgus deformity along with the non union of the of the tibia. Compression with bone grafting was carried out once deformity was corrected. 11 patients had proximal tibial and 5 patients had distal tibial corticotomies.All femoral osteotomies were performed proximally. Postoperatively all patients 


\begin{tabular}{|c|c|c|c|c|c|c|c|c|c|c|c|c|c|c|c|c|c|c|c|c|c|}
\hline \multirow{3}{*}{ 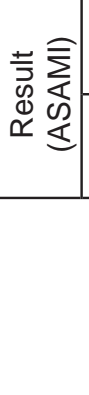 } & ןeuo!̣oun & ш & 0 & $\sqcup$ & ш & 0 & 0 & ५ & $\sqcup$ & 0 & 0 & $ш$ & $ш$ & 0 & 0 & 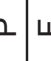 & $\perp 0$ & 20 & 2 & 4 & \\
\hline & Kuog & ш & 0 & 0 & ш & 0 & 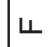 & O & \llcorner & 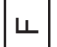 & 0 & ш & ш & 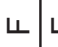 & ४ & 4 & $\perp$ & $\perp<$ & $\perp$ & -10 & \\
\hline & 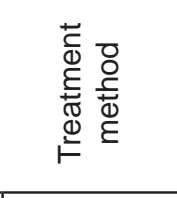 & 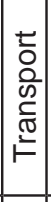 & 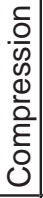 & 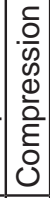 & 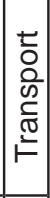 & 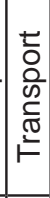 & $-\begin{array}{l}\frac{t}{0} \\
\frac{0}{0} \\
\frac{0}{\sigma} \\
\stackrel{0}{=}\end{array}$ & 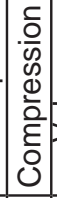 & $\frac{0}{0} \frac{0}{0}$ & 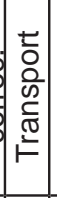 & 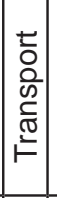 & $\begin{array}{ll}\frac{5}{0} \\
\frac{2}{2} \\
\frac{2}{\pi} \\
\stackrel{0}{2} \\
\end{array}$ & 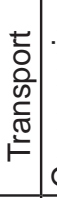 & 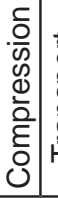 & 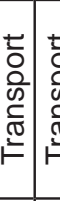 & $\begin{array}{l}\frac{5}{0} \\
\frac{a}{2} \\
\frac{2}{\sigma} \\
=\end{array}$ & 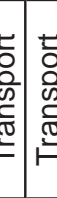 & 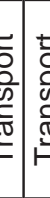 & 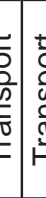 & $=\frac{5}{5}$ & \\
\hline \multirow{3}{*}{ 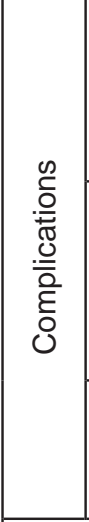 } & 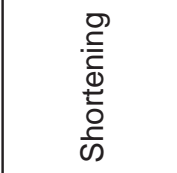 & $\overline{\bar{z}}$ & 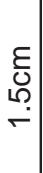 & $\mid \begin{array}{c}\frac{E}{U} \\
\llcorner \\
-i\end{array}$ & $\overline{\bar{z}}$ & $\overline{\bar{z}}$ & $\stackrel{\varepsilon}{\mathcal{U}}$ & $\left|\begin{array}{c|}\varepsilon \\
\bar{U} \\
0 \\
-i \\
-i\end{array}\right|$ & $\overline{\bar{z}}$ & $\left|\begin{array}{l|}\frac{\varepsilon}{U} \\
h \\
-i\end{array}\right|$ & $\overline{\bar{z}}$ & $\overline{\bar{z}}$ & $\overline{\bar{z}}$ & 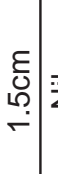 & $\overline{\bar{z}} \overline{\bar{z}}$ & & & & & & \\
\hline & 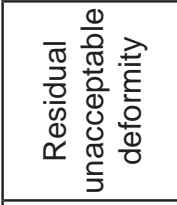 & $\overline{\bar{z}}$ & $\overline{\bar{z}}$ & $\overline{\bar{z}}$ & $\overline{\bar{z}}$ & $\overline{\bar{z}}$ & $\overline{\bar{z}}$ & $\bar{\Sigma}$ & $\bar{z}$ & $\bar{z}$ & $\bar{z}$ & $\overline{\bar{z}}$ & $\overline{\bar{z}} \bar{z}$ & $\overline{\bar{z}}$ & $\overline{\bar{z}} \mid \overline{\bar{z}}$ & $\bar{\Sigma}$ & & $\bar{z} \bar{z}$ & $\bar{z}$ & $\overline{2}$ & \\
\hline & 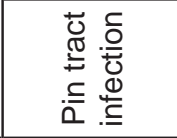 & $1+$ & + & + & + & + & + & + & + & + & + & + & + & + & ++ & ++ & ++ & ++ & $+1+$ & $1+$ & \\
\hline \multicolumn{2}{|c|}{ 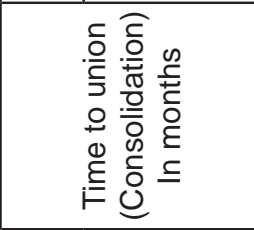 } & $\infty$ & $\infty$ & $\infty$ & 어 & 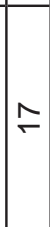 & $\stackrel{\text { }}{\underset{H}{H}}$ & 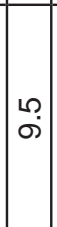 & $\begin{array}{l}L \\
\infty \\
\infty\end{array}$ & \begin{tabular}{|l|}
$L$ \\
$\infty$ \\
$\infty$
\end{tabular} & 아 가 & 我 & a) & $\infty$ & $\Rightarrow \mid \begin{array}{ll}1 \\
\infty\end{array}$ & ح" & & & 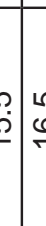 & 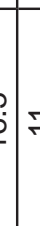 & \\
\hline & 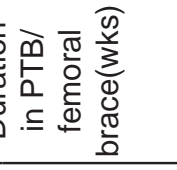 & 0 & ஸ̊ & 0 & 0 & $\wedge$ & $\wedge$ & $\infty$ & 0 & $\left|\begin{array}{l}1 \\
0 \\
0\end{array}\right|$ & $\infty$ & $\infty$ & 0 & $\infty$ & $0 \mid c$ & o & 0 & c & 0.6 & $p<$ & \\
\hline & 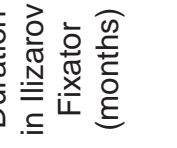 & $\left|\begin{array}{l}0 \\
0\end{array}\right|$ & $\begin{array}{l}0 \\
0 \\
0\end{array}$ & \begin{tabular}{|l}
1 \\
0 \\
0
\end{tabular} & の & $\exists$ & $\exists$ & $\left|\begin{array}{l}n \\
\sigma\end{array}\right|$ & $\stackrel{\sim}{\sim}$ & $\wedge$ & 어 & 㐌 & $\stackrel{\sim}{\sim}$ & $\infty$ & on. & 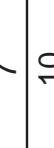 & $\stackrel{\sim}{-1}$ & $y$ & 5 & 0 & \\
\hline & 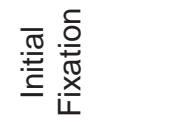 & 岀 & 岀 & $\underline{z}$ & $\stackrel{z}{z}$ & $\underline{z}$ & 岀 & 岃 & $\begin{array}{l}0 \\
0 \\
0\end{array}$ & 岀 & 岀 & $\varliminf_{\vdots}$ & $\begin{array}{l}0 \\
0 \\
0\end{array}$ & 岃 & \begin{tabular}{c|c}
$\frac{\pi}{\frac{\pi}{\alpha}}$ & $\frac{a}{\frac{\pi}{a}}$
\end{tabular} & $\begin{array}{l}\frac{d}{\pi} \\
\frac{\pi}{\alpha}\end{array}$ & $\sum$ & $=4$ & 立 & 㟋 & \\
\hline & 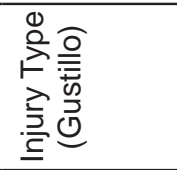 & $\stackrel{\stackrel{m}{=}}{=}$ & $\stackrel{\stackrel{p}{!}}{\equiv}$ & $\stackrel{\mathbb{1}}{=}$ & $\stackrel{\stackrel{p}{!}}{=}$ & $\stackrel{\stackrel{p}{!}}{=}$ & $\mid \begin{array}{l}\stackrel{U}{\equiv} \\
\equiv\end{array}$ & 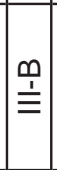 & 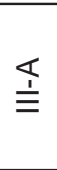 & $\mid \stackrel{\stackrel{p}{=}}{=}$ & 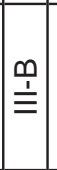 & $\stackrel{\mathbb{1}}{\equiv}$ & $=$ & $\stackrel{\stackrel{p}{=}}{=}$ & 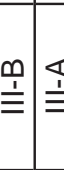 & 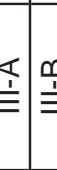 & 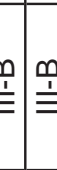 & 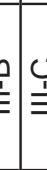 & $\begin{array}{l}\substack{1\\
} \\
\end{array}$ & 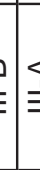 & \\
\hline & $\frac{0}{0}$ & $|\simeq|$ & - & $\simeq$ & $\simeq$ & -1 & - & $\mid \widetilde{\mid}$ & $\simeq$ & $-\Delta$ & -1 & $\simeq$ & - & \lrcorner & $\simeq \square$ & $\Upsilon 10$ & $Y \propto$ & $E-$ & \lrcorner- & 10 & \\
\hline & 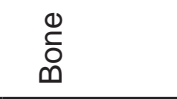 & $\vdash$ & $\vdash$ & $\vdash$ & $\sqcup$ & $\vdash$ & $\vdash$ & $\sqcup$ & $\vdash$ & $\vdash$ & $\sqcup$ & $\sqcup$ & $\vdash$ & $\sqcup$ & $\vdash \mid \vdash$ & -1 & - ш & $L$ & - & 1 & \\
\hline & $\stackrel{\Perp}{\gtrless}$ & $\begin{array}{c}n \\
0\end{array}$ & ળ & 븜 & $\begin{array}{c}0 \\
0\end{array}$ & $\begin{array}{l}\dot{\bar{m}} \\
\dot{\bar{v}}\end{array}$ & ज़ & $\begin{array}{c}0 \\
0\end{array}$ & $\underline{\underline{\underline{ }}}$ & ஸी & \begin{tabular}{|c|c|}
$\infty$ \\
$\circlearrowleft$
\end{tabular} & 心) & $\stackrel{\oplus}{\underline{\underline{u}}}$ & ల) & $\underline{\underline{\omega}}$ & C) & 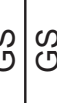 & ?ִ & 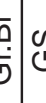 & 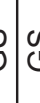 & \\
\hline & 蔍 & $|\Sigma|$ & $\Sigma$ & $\Sigma$ & $\Sigma$ & $\Sigma$ & ४ & $\Sigma$ & $\Sigma$ & $\Sigma$ & $\Sigma$ & $\Sigma$ & $\Sigma$ & $\Sigma$ & $\Sigma u$ & $\perp \sum$ & $\Sigma \Sigma$ & $\sum \Sigma$ & $\geq 4$ & 12 & \\
\hline & $\frac{8}{8}$ & $\stackrel{m}{m}$ & ले & $\stackrel{N}{a}$ & 우 & $\tilde{m}$ & ㅇ & เి & $\stackrel{m}{m}$ & ৩ & ল & $\stackrel{\infty}{\sim}$ & $\stackrel{m}{\sim}$ & $\stackrel{\rightarrow}{\rightarrow}$ & เી & Љ) & 2 in & $n$ & $\begin{array}{l}5 \\
m \\
m\end{array}$ & 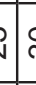 & \\
\hline & $\sum_{i j}^{O}$ & $-1 \mid$ & $N$ & $m$ & $\nabla$ & م & 0 & 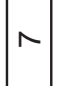 & $\infty$ & or & 위 & 7 & Эิ & $\stackrel{m}{\rightarrow}$ & $\overrightarrow{7}$ & S & 車 & $\exists \rightarrow$ & 0 & $\delta$ & \\
\hline
\end{tabular}


had radiographs of the affected limb taken for assessment of the corticotomy and position of the wires. Corticotomy site distraction was initiated after 10 days at the rate of $1 \mathrm{~mm}$ per day. Compression and distraction technique [Accordian manoeuvre] was employed in 2 patients. Follow up x-rays were done at 3 weeks for assessment of the regenerate and at 4 weeks interval thereafter until fracture union. In doubtful distraction rate was reduced to $0.5 \mathrm{~mm} /$ day until satisfactory appearance on x-rays.

Patients were mobilized with partial weight bearing, within comfort by a trained physiotherapist. They were discharged upon satisfactory compliance and followed up in the out patient department at monthly intervals for assessment of fracture union, regenerate progress and ensuring compliance with physiotherapy. Fixator was retained further for the duration equal to the period of bone transport after bone docking in cases where bone transport was done. The fixator was removed once union was confirmed with conventional x-rays. The operated limb was protected in a functional cast brace for at-least 6 to 8 weeks after removal of fixator.

The period of follow up after fracture union ranged from 8-20 months [Average 13 months]. The outcomes were assessed using the Association for the Study and Application of Methodology of Ilizarov [ASAMI] criteria.

\section{Results}

The patients were followed-up for an average period of 13 months (8 to 20) after removal of the frame. The results were divided into bone and functional results, according to the criteria laid down by the Association for the Study and Application of the Method of Illizarov (13, 14). This classification is applicable for tibial and femoral non-unions.

Bone results were determined according to four criteria: union, infection, deformity and limb-length discrepancy. A fracture was considered to be united when there was no motion at the fracture site following removal of the Illizarov frame and when there was radiological evidence of union. Nine patients received bone grafts. The fracture united in all patients and there were no refractures following removal of the frame. The time to union ranged from eight months to eighteen months (average 12 months). One patient with an angular deformity of 14 degrees of the tibia underwent correction. There was some resultant limb length inequality in ten patients, as listed in the table. None required any procedure to correct the shortening. Superficial pin-tract infections developed in all patients; these resolved with local care and oral antibiotics. In one patient, a broken half-pin was removed and in two patients a single wire was repositioned. All fractures healed with $<5^{\circ}$ of malalignment.

According to the protocol of the Association for the Study and Application of the Method of Illizarov (ASAMI), a bone result cannot be graded excellent unless union was achieved without the use of a bone graft. An excellent result was defined as union, no infection, deformity of less than $7^{\circ}$ and a limb-length discrepancy of less than $2.5 \mathrm{~cm}$. A good result was defined as union and any two of the other three criteria; a fair result, as union and one of the other criteria; and a poor result, as non-union or refracture, or as union but none of the remaining three criteria. The authors used the above classification to evaluate the results of the tibial and femoral non-unions. According to the system, the bone results were excellent in 4 patient, good in 7 patients, and fair in 9 patients.

The functional results were based on five criteria (ASAMI); a significant limp, stiffness of either the knee or the ankle (loss of more than $15^{\circ}$ of full extension of the knee or $15^{\circ}$ of dorsiflexion of the ankle in comparison with the normal contralateral ankle), soft tissue sympathetic dystrophy, pain that reduced activity or disturbed sleep and inactivity (unemployment or an inability to return to daily activities because of the injury). The functional results were considered excellent if the patient was active and none of the other four criteria were applicable; good, if the patient was active but one or two of the other criteria were applicable; fair, if the patient was active but three or four of the other criteria were applicable, and poor, if the patient was inactive regardless of whether other criteria were applicable. Four patients were able to return to work and daily activities. Six were active but had a limp with some pain and stiffness of the ankle and knee joints. Another six, in spite of being active had persistent limb oedema and some degree of pain besides stiffness of the ankle and knee. Five patients had to quit their jobs as they were unable to pursue an active lifestyle. According to these criteria, the functional result was excellent in 4 patients, good in 6 patients, fair in 5 patients and poor in 5 patients. 


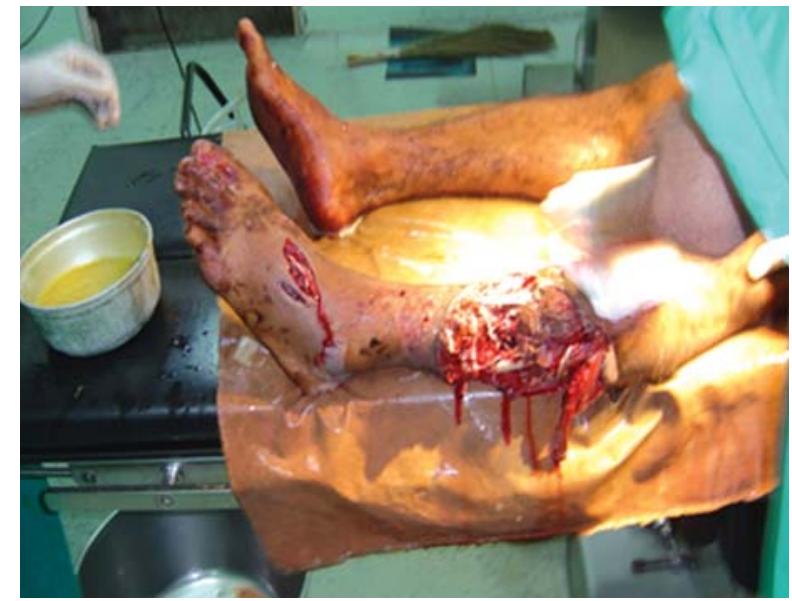

Type III B fracture of Tibia

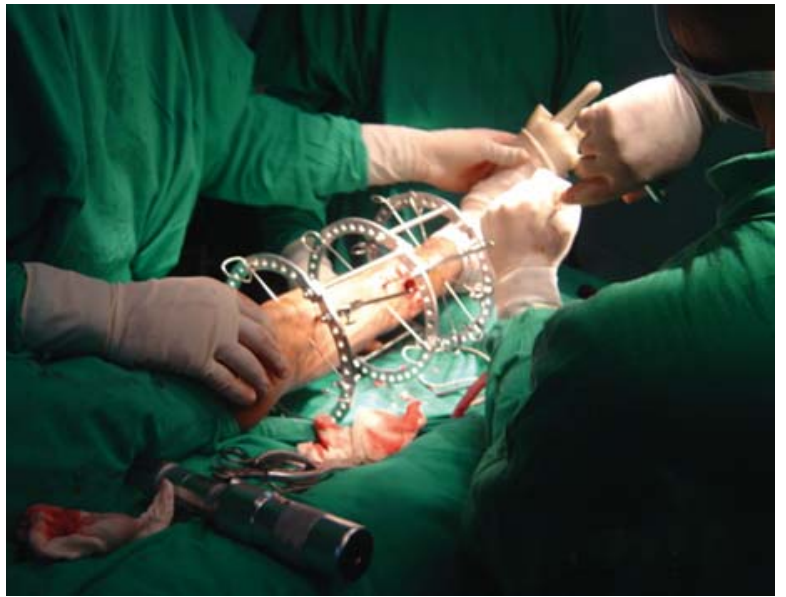

Ilizarov ring fixation

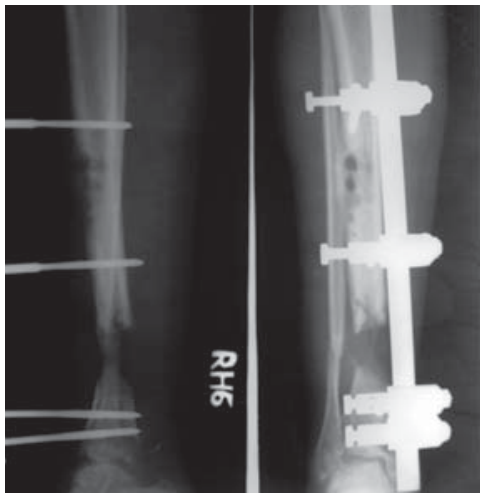

Type IIIb open fracture initially managed with Hoffman fixator Case-I
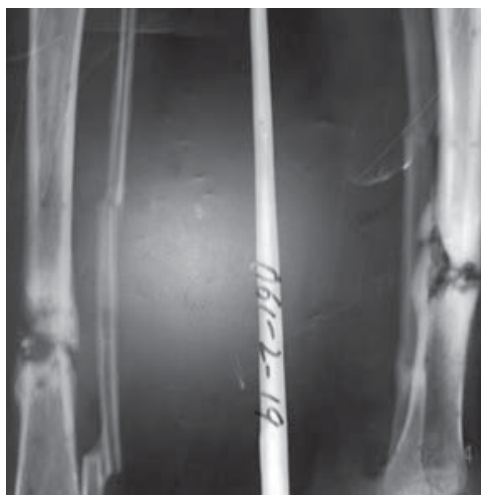

Infected non-union of left tibia

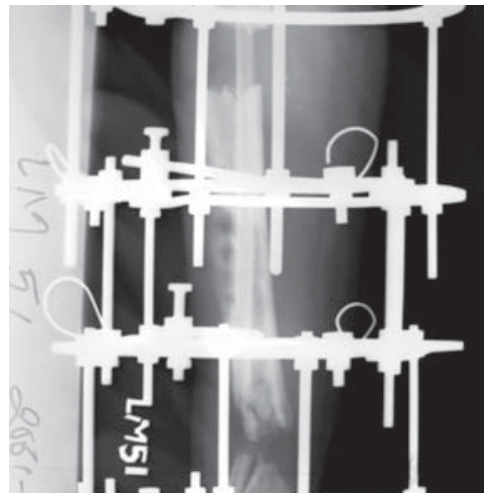

Ilizarov ring fixator applied with corticotomy and bne transport Case-I

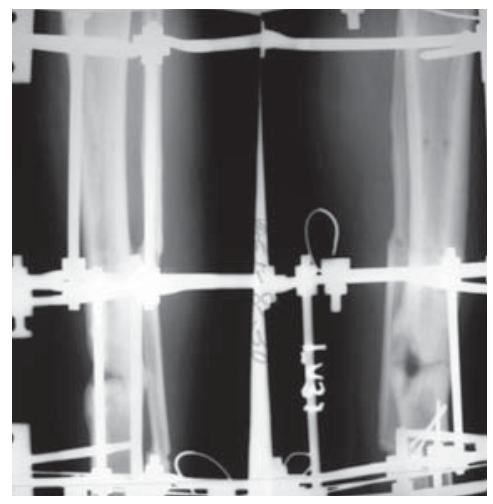

Compression with Ilizarov fixator

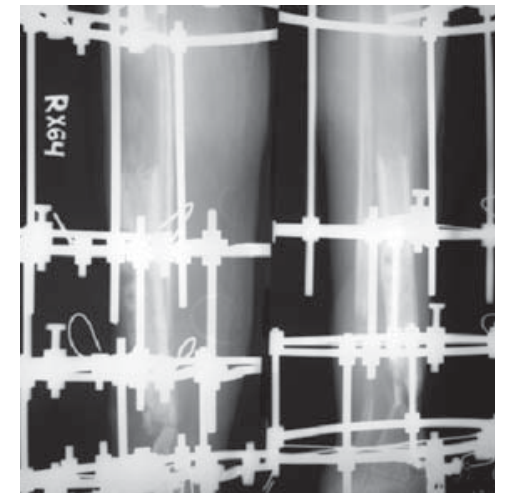

Adequate length achieved,and docking done

Case-I

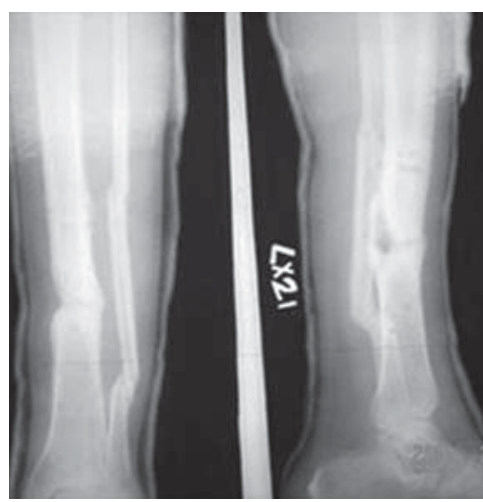

Bony union with functional brace 


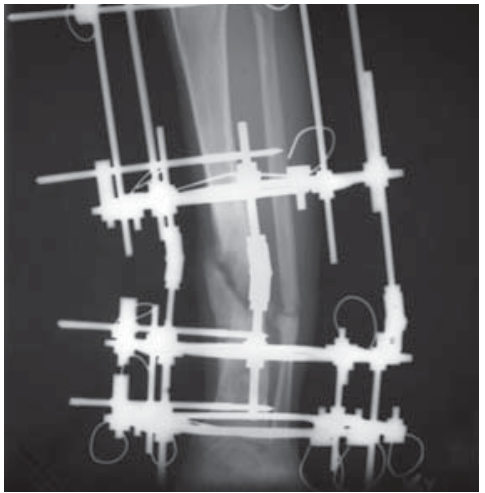

Non union with varus

deformity

Case III

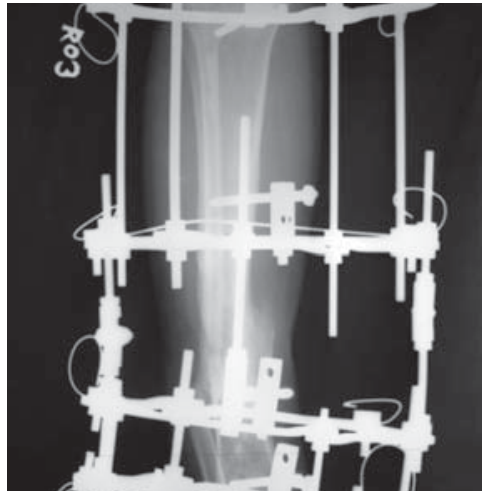

Angulation almost corrected

Case III

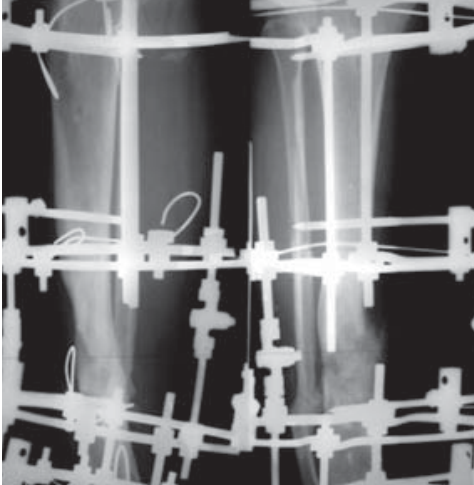

Union achieved

\section{Discussion}

Numerous authors have concluded that intramedullary nail fixation of type-III tibial fractures is the preferred method of stabilization for patients at a civilian trauma center(2-6). Kakar and Tornetta(15) recently reported the results of 143 open tibial fractures treated with protocol-driven wound management and immediate unreamed intramedullary nail fixation, which resulted in minimal complications and a low rate (3\%) of deep infection.

Similarly, monoplanar external fixation has been considered for use in tibial fractures characterized by severe soft-tissue injury because of its ease of placement and the preservation of existing blood supplies to the tibia. However, Henley et al. (16) have found that use of monoplanar external fixation often leads to higher rates of complications, including malunion, infection, and an increased number of operative interventions, and this type of fixation is generally reserved for temporary stabilization.

Compared with injuries sustained in the civilian trauma setting, wounds sustained on the battlefield resulting from an "outside-in" injury mechanism are considered to be more contaminated.(17-19). Moreover, the typical early débridement and coverage protocols espoused by Fischer et al. (20), which lead to a lower rate of infectious complications, are not always possible because of delays associated with evacuation to definitive treatment facilities during wartime. These realities combined with the common occurrence of extensive retained blast fragments throughout the soft tissues in themselves complicate the injury management.. Similar to many other institutions, we have observed the benefits of a protocol-driven approach to the treatment of these limb-threatening injuries, which includes frequent aggressive soft-tissue and osseous débridement, expeditious soft-tissue coverage, and delayed supplemental bone-grafting when needed.(26).

A fracture non-union is a significant problem to the patient and the surgeon. In most instances the patient has undergone one or more surgical procedures, has lost considerable time from his/her job or life style, and has been forced to alter his or her life style. Furthermore, the psychological and physical trauma to the patient when faced with the prospect of another surgery is often underestimated. The problems facing the surgeon are no less formidable. In many instances consolidation of the non-union must be achieved with correction of axial and rotational mal-alignment (21). In our study, all patients with open fractures were being treated with other forms of definitive treatment before being opted for ring fixation. The effects of smoking on the outcome of ring fixation have been well documented (22). Many of the patients in our study were smokers and consumed alcohol. Despite being advised about the consequences of smoking and alcohol intake, it was difficult to ensure complete co-operation from the patients in this regard. The regenerate appearance was not on expected lines in some cases particularly with the distal corticotomies. In one particular case, there was no regenerate visible on the radiographs even at 4 weeks and an accordion man oeuvre was resorted to and distraction rate was reduced until satisfactory regenerate was visible.

We have followed the criteria laid down by ASAMI. The functional result is predetermined by the condition of the nerves, muscles, vessels, joints, and to a lesser 
extent the bone (23). Ankle pain with disability is the major source of residual disability after successful use of the llizarov device for the treatment of Tibial nonunion even after fracture union (24). No patient in our study had any residual neurovascular deficits but the correlation between bony and functional results was poor. This is largely due to the soft tissue status particularly oedema and joint stiffness. In our study, all patients had varying degrees of knee, ankle and subtalar joint stiffness. Though knee stiffness was largely overcome with physiotherapy, foot and ankle stiffness persisted and worsened despite bony union. This may account for the poor functional outcome in our cohort of patients.

ASAMI criteria define unemployment as a poor result. Majority of patients who were assessed for functional results did not go back to their original employment. Most changed their jobs to a sedentary and less demanding work as they did not have any choice. Other studies $(25,26)$, have highlighted that patient satisfaction is more important than employment status in assessment of functional status. This is true in developed countries, where there is adequate government support for economic inactivity. In developing countries like Nepal no such support exists. Therefore the direct applicability of the ASAMI criteria in the Indian scenario may not be appropriate for a finite functional analysis. Though many from our study were happy in that an amputation was avoided, most of them felt that this was at a 'heavy price' and some still preferred an amputation in the hope of early return to work and pain relief.

\section{Conclusion}

Our observations indicate that the llizarov method is not a panacea but an important treatment method for surgeons, in situations such as osteomyelitis, osteopenia, complex deformities and significant limblength inequalities. The drawbacks of this method are the time and resource, intensive nature of the treatment, the difficulties of prolonged fixator use and the potential major and minor complications. The surgeon should know when to offer an amputation as this is, in certain circumstances, the best option. Therefore the treatment in these situations needs to be highly individualised.

In conclusion, we believe that llizarov ring fixation that has resulted in a relatively low rate of complications and definite fracture union for severe open fractures of the long bones of the lower extremity resulting from war injuries. Ring external fixation in these patients appears to be a valuable form of treatment allowing the added benefit of immediate weight-bearing without hardware retention after fracture-healing.

\section{References}

1. Owens BD, Kragh JF Jr, Macaitis J, Svoboda SJ, Wenke JC. Characterization of extremity wounds in Operation Iraqi Freedom and Operation Enduring Freedom.J Orthop Trauma.2007 ; 21:254-7.

2. Bone LB, Kassman S, Stegemann P, France J. Prospective study of union rate of open tibial fractures treated with locked, unreamed intramedullary nails. J Orthop Trauma. 1994;8:459.

3. Tielinen L, Lindahl JE, Tukiainen EJ. Acute unreamed intramedullary nailing and soft tissue reconstruction with muscle flaps for the treatment of severe open tibial shaft fractures. Injury. 2007;38:906-12.

4. Kakar S, Tornetta P 3rd. Open fractures of the tibia treated by immediate intramedullary tibial nail insertion without reaming: a prospective study. J Orthop Trauma. 2007;21:153-7.

5. Gopal S, Majumder S, Batchelor AG, Knight SL, De Boer P, Smith RM. Fix and flap: the radical orthopaedic and plastic treatment of severe open fractures of the tibia. J Bone Joint Surg $\mathrm{Br}$. 2000;82:959-66.

6. Sanders R, Jersinovich I, Anglen J, DiPasquale T, Herscovici D Jr. The treatment of open tibial shaft fractures using an interlocked intramedullary nail without reaming. J Orthop Trauma. 1994;8:50410.

7. Jorgenson DS, Antoine GA. Advances in the treatment of lower extremity wounds applied to military casualties. Ann Plast Surg. 1995;34:2.

8. Lerner A, Fodor L, Soudry M. Is staged external fixation a valuable strategy for war injuries to the limbs? Clin Orthop Relat Res. 2006;448:217-24.

9. Dubravko $\mathrm{H}$, Zarko R, Tomislav $\mathrm{T}$, Dragutin $\mathrm{K}$, Vjenceslav N. External fixation in war trauma management of the extremities-experience from the war in Croatia. J Trauma. 1994;37:831.

10. Zeljko B, Lovrć Z, Amć E, Busić V, Lovrć L, Markov ć I. War injuries of the extremities: twelve-year follow-up data. Mil Med. 2006;171:55-7. 
11. Duman H, Sengezer M, Celikoz B, Turegun M, Isik S. Lower extremity salvage using a free flap associated with the llizarov method in patients with massive combat injuries. Ann Plast Surg. 2001;46:108-12.

12. Andersen RC, Frisch HM, Farber GL, Hayda RA. Definitive treatment of combat casualties at military medical centers. J Am Acad Orthop Surg. 2006;14(10 Suppl):S24-31.

13. Maiocchi AB, Aronson J. Non-union of the femur. IN: Operative principles of Illizarov. Fracture treatment, non-union, osteomyelitis, lengthening, deformity correction. Baltimore: Williams and Wilkins; 1991: 245-62.

14. Catagni M, Villa A. Non-union of the leg (tibia). IN: Operative principles of Illizarov: Fracture treatment, non-union, osteomyelitis, lengthening, deformity correction. Baltimore: Williams and Wilkins; 1991: 199-214.

15. Kakar S, Tornetta P 3rd. Open fractures of the tibia treated by immediate intramedullary tibial nail insertion without reaming: a prospective study. J Orthop Trauma. 2007;21:153-7.

16. Henley MB, Chapman JR, Agel J, Harvey EJ, Whorton AM, Swiontkowski MF. Treatment of type II, IIIA, and IIIB open fractures of the tibial shaft: a prospective comparison of unreamed interlocking intramedullary nails and half-pin external fixators. J Orthop Trauma. 1998;12:1-7.

17. Islinger RB, Kuklo TR, McHale KA. A review of orthopedic injuries in three recent U.S. military conflicts. Mil Med. 2000;165:463-5.

18. Hayda R, Harris RM, Bass CD. Blast injury research: modeling injury effects of landmines, bullets, and bombs. Clin Orthop Relat Res. 2004;422:97-108.
19. Covey DC. Blast and fragment injuries of the musculoskeletal system. J Bone Joint Surg Am. 2002;84:1221-34.

20. Fischer MD, Gustilo RB, Varecka TF. The timing of flap coverage, bone-grafting, and intramedullary nailing in patients who have a fracture of the tibial shaft with extensive soft-tissue injury. J Bone Joint Surg Am. 1991;73:1316-22.

21. Kempf I, Grosse A, Rigaut P. The treatment of noninfected pseudarthrosis of the femur and tibia with locked intramedullary nailing. Clin Orthop. 1986;212:142-545.

22. McKee Michael D, DiPasquale Dennis J, Wild Lisa M, Stephen David JG, Kreder Hans J, Schemitsch Emil H. The Effect of Smoking on Clinical Outcome and Complication Rates Following Ilizarov Reconstruction. J Orthop Trauma. 2003;17:663667.

23. Paley D, Catagni MA, Argnani F, Villa A, Benedetti GB, Cattaneo R. Ilizarov treatment of tibial nonunions with bone loss. Clin Orthop Relat Res. 1989:146-65.

24. Sanders DW, Galpin RD, Hosseini M, MacLeod MD. Morbidity resulting from the treatment of tibial nonunion with the llizarov frame. Can J Surg. 2002;45:196-200.

25. Patil S, Montgomery R. Management of complex tibial and femoral nonunion using the llizarov technique, and its cost implications. J Bone Joint Surg Br. 2006;88:928-32.

26. Marsh DR, Shah S, Elliott J, Kurdy N. The Ilizarov method in nonunion, malunion and Infection of fractures. J Bone Joint Surg Br. 1997;79:273-9. doi: 10.1302/0301-620X.79B2.6636. 